0.0009. Those referred in for end of life care was 27 vs 35 . Of those that died during their admission there was no difference in the length of stay 12.2 vs 10.1 days, $\mathrm{p}=0.41$. There was no significant difference in length of stay prior to starting the care and communication record, 9.4 vs 5.6 days, $\mathrm{p}=0.06$.

Conclusions Though there were no differences in numbers of admission during the COVID 19 pandemic. There were significant differences in the length of stay. It was thought that the those coming in during the pandemic were more likely to be coming in for end of life care but as no significant difference between length of stay of patients that died nor in how quickly they were started on the care and communication record this was not the case. This information should be considered when improving current discharge processes.

\section{EXPERIENCE OF COVID-19 IN A HOSPICE INPATIENT UNIT: CHARACTERISTICS, SYMPTOMS AND ETHICAL ISSUES}

Emma Gardner, Emma Tempest. St Helena Hospice

\subsection{6/spcare-2021-PCC.29}

Objectives One of the established risk factors for death from coronavirus disease 2019 (COVID-19) is comorbidity. Patients referred to palliative care before developing COVID-19 infection are therefore more vulnerable due to their pre-existing conditions. This study aimed to describe the impact of COVID-19 infection on hospice inpatients.

Methods A retrospective review was performed of patients with confirmed COVID-19 during an admission to one hospice inpatient unit in the five months between 1st March 2020 and 31st July 2020.

Results 12 patients were identified with confirmed COVID19. Mortality during the admission was $67 \% \quad(n=8)$. Patients had a median age of 74 , were $75 \%$ male and had a median Australia-modified Karnofsky Performance Status (AKPS) of 30. 100\% had comorbidities, most commonly malignancy (58\%), hypertension $(50 \%)$ and diabetes $(50 \%)$. The symptoms most frequently recorded were confusion (67\%), agitation (67\%), fever (50\%), cough (50\%) and breathlessness (50\%). Symptoms at the end of life were treated with subcutaneous infusion (100\%) using commonly prescribed medications (oxycodone used in 75\%, morphine $13 \%$, midazolam 88\%, levomepromazine 63\%, glycopyrronium 88\%, haloperidol 13\%) and doses. A third of cases were detected by a routine COVID-19 swab, however this policy led to ethical debate around testing in the last days of life.

Conclusions This small case series suggests that larger studies into symptoms of COVID-19 at the end of life and their control would be helpful, particularly if they take into account baseline (and the impact on those with palliative conditions or frailty) and collect data from community settings as well as hospital care. We understand that there is heterogeneity in COVID-19 testing policies at hospices across the UK, and feel further discussion around the ethical questions raised by testing, particularly at the end of life, would be beneficial in finding our way forward in this ever-changing pandemic landscape.

\section{REFLECTIONS ON PALLIATIVE CARE HEALTH CARE PROFESSIONALS' NEEDS DURING THE FIRST WAVE OF THE COVID-19 PANDEMIC 'THEMATIC ANALYSIS OF A POSTGRADUATE COHORT OF STUDENTS' DISCUSSION BOARD}

Fiona Rawlinson, Ross Smith, Toby Dinnen, Ed Hayes, Karianne Harper, Tony Duffy, Tamarha Jones, Lucy Thomas, Jo Clarke, Anjum Joad, Rajam lyer, Rachael Marcheant, Melissa Day, Matt Hooper, Lisa Bailey, Gayathri Subramaniam, Deepa Khurana, Wendy Wolfe, Sivakumar lyer, Lipika Patra, Daniel Barry, Diana Lees, Heidi Leeder, Catriona McKeating, Sian Gallard. Cardiff University

\subsection{6/spcare-2021-PCC.30}

background/Introduction The Covid-19 pandemic created immense unexpected pressure on postgraduate health care professional students undertaking academic study. The role of a community of practice within an international cohort of postgraduate students became apparent as the pandemic progressed. Needing a supported space away from social media in which to discuss developing issues, and a forum in which useful resources could be shared swiftly became apparent. A closed 'Discussion board' facility was used within the virtual learning platform in which themes and collections of support, ideas and materials were developed.

Methods Qualitative thematic analysis of anonymised contributions to the Discussion board 25th March 2020 - 31st July 2020. Permission was sought retrospectively from all participants on the Discussion Board; any information from those not willing for their content to be included was deleted from the transcripts before review. The transcripts were reviewed by 2 independent researchers for content and context.

Results 13 themes developed. Sharing resources (March); ethical issues, communication skills (including virtual communication), symptom control, team support and leadership, the challenge of covid 19 in remote communities, the collateral damage of the pandemic for children, involving the family remotely and maintaining one's own wellbeing in a pandemic ( April); Developing services, moving forward and quality improvement ( May); moral courage and managing the symptom of breathlessness (June).

Conclusions The generation of themes reflected the unprecedented challenges of the phase of the pandemic being experienced. Symptom control, communication skills and ethics leading to their application in different settings and the need after the first few weeks for team support, mental resilience and leadership. Valuable reflections and resources have been developed to help support future surges.

\section{SUPPORTING COMMUNITY PALLIATIVE CARE RESOURCES IS VITAL IN THE CONTINUING PANDEMIC}

Fiona Rawlinson, Margred Capel, James Davies, Susan Rees. City Hospice, Cardiff

\subsection{6/spcare-2021-PCC.31}

Background Covid-19 had a dramatic effect on the delivery of health care across all settings: institutions reduced footfall and strict social distancing measures were introduced. Face to face consultations were reduced; referrals to a community palliative care team (CPCT) increased. Referral data was explored for trends in referral patterns that might inform optimal use of resources. 